\title{
VILA-MATAS PENSA EM SUA ARTE: OS (DES)CAMINHOS DA FICÇÃO CRÍTICA
}

Nadier Pereira dos Santos*

Resumo: Este artigo pretende verificar como em “Chet Baker piensa en su arte" o escritor catalão Enrique Vila-Matas faz ficção e reflexão crítica coexistirem ao analisar as relações da linguagem literária com a realidade. Nesse texto, por meio de mais um experimento com os gêneros, ao estilo dos que caracterizam livros como Bartleby e companhia e 0 mal de Montano, Vila-Matas tenta escapar das formas convencionais de exposição crítica ao conceber um narrador que, saltando de Joyce a Simenon ou de Stevenson a De Maistre, vai delineando um caminho errático no qual as fronteiras entre o ensaio e a narração são constantemente questionadas. Tratase aqui de observar de que maneira o jogo estabelecido pelo autor constitui uma tentativa de examinar as possibilidades que tem a ficção literária de contestar e oferecer novos caminhos aos meios tradicionais de sua crítica.

PALAVRAS-CHAVE: Ensaio; Crítica; Ficção; Vila-Matas.
* nadiers@yahoo.combr

Mestre em Literatura Comparada pela UFRN.

RESUMEN: Este artículo pretende verificar como en "Chet Baker piensa en su arte" el escritor catalán Enrique Vila-Matas hace coexistir ficción y reflexión crítica al analizar las relaciones del lenguaje literario con la realidad. En ese texto, a través de un experimento más con los géneros, al estilo de los que caracterizan libros como Bartleby y compañía y El mal de Montano, Vila-Matas intenta escapar de las formas convencionales de exposición crítica al concebir un narrador que saltando de Joyce a Simenon o de Stevenson a De Maistre delinea un camino errático en el cual las fronteras entre el ensayo y la narración son constantemente cuestionadas. Se trata aquí de observar de qué manera el juego establecido por el autor es un intento de examinar las posibilidades que tiene la ficción literaria para contestar y ofrecer nuevos caminos a los medios tradicionales de su crítica.

PALABRAS CLAVE: Ensayo; Crítica; Ficción; Vila-Matas. 


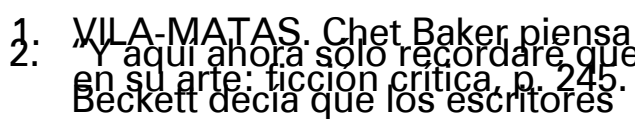

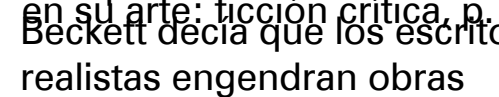
discursivas porque se centran en hablar sobre las cosas, sobre un asunto, mientras que 'el arte auténtico no hace eso: el arte autentico es la cosa y no algo sobre las cosas: Finnegans Wake no es arte sobre algo, es el arte en sí." In: VILA-MATAS. Chet Baker piensa en su arte: ficción crítica, p. 246. Em "Panaroma em português", Haroldo de Campos também destaca a citação de Samuel Beckett: a obra "não é sobre alguma coisa. É ela própria essa alguma coisa". Segundo o autor, a citação encontra-se em Our Exagmination Round His Factification For Incamination of Work In Progress, coleção publicada em 1929 que reúne textos críticos de Beckett e outros autores a respeito do Finnegans Wake, este lançado em 1939 e at então conhecido apenas como "Work in Progress".
Outrora separados pelo mito gasto do "soberbo criador e do humilde servidor, ambos necessários, cada um no seu lugar etc.", o escritor e o crítico se

Roland Barthes, Crítica e verdade.

Logo no início de "Chet Baker piensa en su arte", texto do escritor catalão Enrique Vila-Matas publicado em 2011, seu narrador reflete a respeito da realidade a partir de uma janela. Um pensamento a respeito dela o inquieta: o fato de julgá-la sem significado, muda e brutal a contrapõe à simplicidade inerente a uma ordem narrativa que pretenda representá-la, dispô-la em uma sequência de acontecimentos que se sucedem. Segundo ele: "Nos tranquiliza la simple secuencia la ilusoria sucesión de hechos. Sin embargo, hay una gran divergencia entre una confortable narración y la realidad brutal del mundo" 1 .

Ainda nos passos iniciais da exposição de sua problemática, o narrador afirma crer que a não narratividade, considerada do ponto de vista convencional, do Finnegans Wake, de James Joyce, é arte pura ${ }^{2}$, assim como considera sumamente artística a habilidade narrativa de um livro como Les fiançailles de Monsieur Hire, de Georges Simenon. Para ele, o caráter inenarrável de Finnegans Wake é o tipo de escrita que melhor corresponde à realidade incompreensível, porém, a simplicidade narrativa inerente à Les fiançailles de Monsieur Hire aproxima-se a uma ordem constantemente buscada na realidade, algo que busca contrapor-se à fragmentação desta e que carrega em si justamente a simplicidade da qual ela carece.

Por isso, o narrador prefere pensar que "[...] está en el fondo todo entrelazado y no tiene por qué haber una división radical, tan sólo una lábil frontera”’. Assim, a reflexão é voltada para a exploração de dois modos de lidar com a realidade por meio da linguagem: a via Finnegans e a via Hire. É quando o narrador passa a comentar Mis dos mundos, de Sergio Chejfec, exemplo de livro que, segundo ele, está mais próximo da linha Finnegans, embora construa sua história atendo-se às convenções narrativas, ou seja, mantendo um fio Hire. Ainda segundo ele, livros dessa natureza, Finnegans com rosto Hire, ao tentar conciliar as duas tendências, camuflando um discurso Finnegans sob uma narratividade Hire, abrem um espaço muito interessante para o romance do futuro.

O narrador também crê possuir esses dois rostos e, embora prefira sua tendência Finnegans, quer averiguar qual sua relação com seu lado Hire. Ele está apenas no início de seu texto, deseja que este seja um radical texto secreto, ou seja, será lido apenas por ele, o que o livrará, portanto, do fracasso público e lhe permitirá maior liberdade para verificar o surgimento de seu lado mais Finnegans. Porém, sabe do risco existente, teme assumir completamente a linha Finnegans e
3. VILA-MATAS. Chet Baker piens en su arte: ficción crítica, p. 247.
EM TESE
BELO HORIZONTE
v. 20
N. 3
SET.-DEZ. 2014
SANTOS. Vila-Matas pensa em sua arte: Os (des)caminhos da ficção crítica $\quad$ P. 107-118 
4. VILA-MATAS. Chet Baker piensa en su arte: ficción crítica, p. 259 tornar-se ilegível, mesmo para si. Por esse motivo, não quer renunciar por completo às vantagens da tendência Hire. No fundo, trata-se de risco e desafio sempre presentes na atividade do escritor, isto é, na tentativa de desenvolver uma escrita que se concilie de maneira artística com uma imagem que se tem da realidade, atividade na qual, para o narrador, um movimento brusco pode representar um erro.

Dessa forma, o objetivo do narrador seria encontrar um modo de unir as duas tendências, mais especificamente, explorar as possibilidades de impor elementos Finnegans a textos Hire para aproximar-se do que chama "arte autêntica", buscar certa harmonia na realidade que concebe enquanto antagônica e ilegível através de um expediente que a torne mais legível, mesmo que mais artificial. Em suas palavras, seu problema seria: “¿Cómo reconciliar realidad y ficción logrando encima que ésta, al pasar a ser tan salvaje e indescifrable como la realidad, se vuelva de pronto, ante nuestros maravillados ojos, plenamente legible?" ${ }^{4}$. A união da via Hire com a Finnegans teria por objetivo encontrar uma medida capaz de abandonar os estilos e formas acomodados e convencionais, retirar a língua de seus usos habituais para alcançar uma forma artística capaz de atingir a emoção do leitor, fazendo-o reconhecer-se em sua interioridade mais oculta e mudar sua relação com a realidade.

Pode-se perceber que por detrás das palavras do narrador também está em jogo a tensão entre as formas literárias do passado e do presente. Para ele, "[...] la historia de la novela ha sido desde sus inicios la historia de una rebelión constante y extrema contra las leyes o costumbres in-

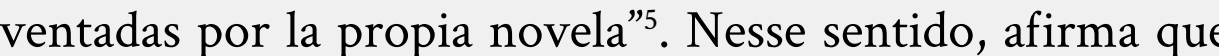
Wiltold Gombrowicz é um exemplo de vanguardista que jamais abandonava a aparência, antes a fazia conviver com a indisciplina. Os experimentos vanguardistas do autor jamais perdiam de vista a tradição, assim, segundo o próprio Gombrowicz, fazendo da Forma a paródia da Forma, ele se apoia nas formas tradicionais, por serem as mais perfeitas e às quais os leitores estão habituados, mas escapa delas para aproximar-se de uma concepção contemporânea do mundo $^{6}$. É nesse contexto que o narrador percebe que perder sua máscara Hire seria insensato. Percebe que essa máscara pode permitir-lhe, e isso é o que aqui interessa, "[...] parodiar, sin perder las formas, la Forma - tan fosilizada, por cierto - del ensayo crítico habitual"

É bastante conhecido o caráter experimental da escrita de Vila-Matas. O autor desenvolve um trabalho que em muitos casos possibilita que uma proposta crítica percorra o interior de uma ficção que se volta sobre si mesma para pensar as condições da literatura contemporânea. Vila-Matas é responsável por uma literatura de caráter fortemente intertextual
5. VILA-MATAS. Chet Baker piensa en su arte: ficción crítica, p. 253.

6. "En cierto sentido, Ferdydurke supone una parodia del cuento
filosófico al estilo volteriano. Transatlántico es la parodia de un relato de los viejos tiempos, del tiempo anticuado y estereotipado. La pornografía enlaza con el género de la amable novela rural polaca. Cosmos tiene algo de nolaca. Cosmos tiene algo de el contrabando de la indisciplina más actual en viejos carricoches del tipo de Transatlántico o de La pornografía me va mucho!" In: GOMBROWICZ, Wiltold. apud In: GOMBROWICZ, Wiltold. apud en su arte: ficción crítica, p. 254.

7. VILA-MATAS. Chet Baker piensa en su arte: ficción crítica, p. 255. 
8. Cf. PIGLIA. La lectura de la ficción, p. 10-11. Complementarmente, destaca-se aqui a seguinte declaraçāo de Roland Barthes: "Nada e mais essencial a uma sociedade que a classificaçao de suas linguagens. Mudar essa classificaçao, deslocar a fala, fazer uma revolução. Duran francês se definiu pela separação pela hierarquia e pela estabilidade de suas escrituras a estabilidade de suas escrituras, e a revolução romântica considerou-se ela própria como uma desordem da classificação. Ora, há mais ou menos cem anos, desde remanejamento imporidam lugares de nossa literatura dos em curso: o que se troca se emcurso: o que se troca, se funcão, poética e crítica, da escritura; não só os escritor fazcm mazem mas sua obra, frequentemente, anuncia as condiçôes de seu nascimento (Proust) ou mesmo de sua ausencla (Blanchot). Uma mesma linguagem tende a circular por toda a literatura, e até por detrás dessa própria tinguagem; O livro é assim tomado pelo avesso por aquele que o faz; não há mais poetas nem romancistas: há apenas uma escritura." In. BARTHES. Crítica verdade, p. 209-210. que, através de seus próprios meios, aborda seus limites e impasses tentando fazer com que surjam novas possibilidades criativas de escrita. $\mathrm{Na}$ tentativa de dar aos seus textos uma enorme liberdade, são comuns, por exemplo, suas experimentações com os limites dos diversos gêneros na intenção de redefinir suas relações e seus limites e a mescla de elementos verdadeiros e fictícios, tais como obras, autores ou citações.

Essa prática consciente da escrita, na qual a narração é acompanhada de perto e complementada por um viés crítico, revela seu alcance e seus variados matizes na medida em que o leitor entende os jogos proposto pelo autor, na medida em que se propõe a visitar as variadas leituras a partir das quais seus textos são construídos. Ricardo Piglia, exemplo de escritor e crítico, afirma não acreditar que existam escritores sem teoria e lembra que, tradicionalmente, alguns dos melhores críticos são artistas, os casos de Pound, Brecht e Valéry são exemplos disso. Piglia lembra ainda que Baudelaire, um crítico excepcional, foi o primeiro a dizer que é cada vez mais difícil ser artista sem ser crítico ${ }^{8}$. VilaMatas é mais um exemplo que confirma o que diz Piglia e Baudelaire, em sua obra nem sempre é simples descrever com clareza as fronteiras que delimitam os espaços onde narração e crítica se inscrevem, uma vez que são comuns os momentos nos quais uma se perde na outra. Na nota do

editor que abre a antologia de sua narrativa breve, Chet Baker piensa en su arte: relatos selectos, publicada em 2011, lê-se que "la vocación eminentemente proteica de su narrativa ha fundado un nuevo género donde el relato se pierde en el ensayo y explora la novela a lo largo de un trayecto crítico que se describe paulatinamente [...]" ${ }^{\prime}$. Essa dupla natureza faz com que em muitas ocasiões seus enredos e o destino de seus personagens sejam apenas pretexto para desenvolver a reflexão crítica. Exemplos destacados disso são encontrados em Bartleby e companhia (2000) e O mal de Montano (2002).

Em mais um experimento com os gêneros, em "Chet Baker piensa en su arte" o autor faz a voz do escritor e a voz do crítico se alternarem para constituir o que denomina "ficção crítica”. Nesse texto fica claro como em Vila-Matas crítica e ficção, comentário e enredo dividem o mesmo espaço e se confundem quando diante de um questionamento literário. A atitude do narrador ante a Forma "tan fosilizada" do ensaio crítico habitual faz com que o texto represente de maneira exemplar a tensão que atravessa boa parte da obra de VilaMatas, tensão decorrente da natureza dupla de sua literatura. É natural que o autor está longe de propor respostas prontas ou definitivas, trata-se antes da tentativa de explorar uma vez mais os limites e possibilidades do texto literário.

De acordo com a concepção de Theodor W. Adorno exposta em "O ensaio como forma", no ensaio são privilegiados
9. Cf. VILA-MATAS. Chet Baker piensa en su arte: relatos selectos, p. 7
EM TESE
BELO HORIZONTE
v. 20
N. 3
SET.-DEZ. 2014
SANTOS. Vila-Matas pensa em sua arte: Os (des)caminhos da ficção crítica $\quad$ P. 107-118 
10. Trata-se predominantemente de Bela Lugosi's Dead, interpretada em uma série de versões por diversas bandas: Nouvelle Vague, Bauhaus, New Holland, Tipperary Club. os aspectos relacionados à experiência individual, à experimentação e à liberdade na escolha e disposição dos elementos da análise empreendida, características que possibilitam ao texto ensaístico um potencial capaz de rivalizar e ultrapassar a rígida exposição e a rigorosa fundamentação conceitual habituais. Em "Chet Baker piensa en su arte", Vila-Matas vale-se dessa liberdade característica do ensaio para privilegiar, em detrimento de uma exposição sistemática, a experiência errante do pensamento de seu narrador e fazer coexistirem narração e crítica numa reflexão acerca da linguagem literária. Será no cruzamento dos elementos que permeiam a experiência individual de um narrador às voltas com uma investigação a respeito da linguagem literária que se vislumbrará a possibilidade de repensar as formas estabilizadas da exposição crítica.

No que diz respeito à parte narrativa do texto, pode-se destacar que o narrador é um crítico literário que partiu em viagem pela manhã desde Madrid, cidade onde vive. No momento em que escreve, encontra-se em Turim, mais especificamente em um quarto na rua Pó, acompanhado de uma biblioteca portátil composta por vinte e um livros que levou consigo. Fica-se sabendo que ele acabara de acordar quando começou a escrever, que começa a escrever sonolento, mas conforme medita e escreve vai despertando completamente. As músicas que o acompanham por toda a noite são também informadas ao leitor conforme sua execução ${ }^{10}$, assim como o passar das horas, quase como se fossem a pontuação indiferente aos pensamentos do narrador. De forma breve, a ação se passa completamente no quarto enquanto o narrador escreve o texto que se tem em mãos, começando à meia-noite e refletindo inteiramente tanto as dificuldades e respostas encontradas quanto os artifícios utilizados pelo crítico durante a madrugada para pensar a respeito das possibilidades oferecidas pelas vias Finnegans e Hire nas suas respectivas relações com a realidade. O resultado é um texto, do ponto de vista da exposição do tema, pouco linear ou sistemático, onde as ideias são desenvolvidas e associadas umas às outras conforme seu surgimento e onde as circunstâncias a partir da quais elas vão surgindo também são apresentadas.

Já quanto aos elementos da análise, a escolha do narrador por Finnegans Wake ${ }^{11}$ como representante da parcela da realidade que se furta à narração é bastante justificável quando se considera as seguintes palavras de Augusto e Haroldo de Campos:

O Finnegans Wake, mais ainda que o Ulisses, assinala o dissídio com a era da representação (do romance como raconto ou fabulação) e instaura, no domínio da prosa, onde se movia o realismo oitocentista com seus sucedâneos e avatares, a era d textualidade, a literatura do significante ou do signo em sua materialidade mesma (se o realismo subsiste, este será agora de natureza estritamente semiótica). ${ }^{12}$
11. "Fluente adivinha e resposta fluida, Finnegans Wake e uma poderosa alegoria da queda e ressurreição da humanidade. É um estranho livro, um misto de fábula, sinfonia e pesadelo - um monstruoso enigma a acenar imperiosamente dos abismos sombrios do sono. Sua mecânica assemelha-se à de um sonho, um sonho que libertou o autor das necessidades da lógica comum, possibilitando-Ihe comprimir todos os períodos da história, todas as fases do desenvolvimento individual e racial, em um desenho circular, de que cada parte é começo, meio e fim." In: CAMPBELL; ROBINSON. Introdução a um assunto estranho, p. 151.

12. CAMPOS; CAMPOS. Panaroma do Finnegans Wake, p. 24

\begin{abstract}
EM TESE
BELO HORIZONTE

v. 20

N. 3

SET.-DEZ. 2014

SANTOS. Vila-Matas pensa em sua arte: Os (des)caminhos da ficção crítica $\quad$ P. 107-118
\end{abstract}


13. Atentar que aqui há um jogo com as palavras: Pan-aroma e não Panorama. Segundo os autores a palavra envolve PAN+AROMA+PANORAMA. Cf. CAMPOS; CAMPOS. Panaroma do Finnegans Wake, p. 198 e 203

\section{CAMPOS; CAMPOS. Panaroma} do Finnegans Wake, p. 21.

\section{CAMPBELL; ROBINSON.} estranho, p. 152.

16. JOYCE, James. apud CAMPOS. Outras palavras sobre Finnegans Wake, p. 195.
Em Panaroma ${ }^{13}$ do Finnegans Wake, Augusto e Haroldo de Campos afirmam que "Finnegans Wake é 100\% de inovação linguística. Nenhuma concessão. Nenhum recuo” ${ }^{14}$. Além disso, em contraste com a simplicidade narrativa assinalada pelo narrador de "Chet Baker piensa en su arte" a respeito de Simenon, pode-se destacar o que diz Joseph Campbell e Henry Morton Robinson acerca da leitura do Finnegans Wake. Para estes autores, é evidente que se trata de um livro que "[...] não pode ser folheado por mãos indolentes. Empreita a imaginação, exige disciplina e tenacidade dos que querem segui-lo na aventura. [...] Não se espere alcançar um entendimento completo num primeiro e ávido embate; na verdade, pode-se não lográ-lo nunca"15. Por fim, como se pode ler em "Outras palavras sobre Finnegan Wake", de Augusto de Campo, Forrest Read esclarece que o próprio Joyce se defendia das acusações de obscuridade argumentando que "uma grande parte da existência dos seres humanos se passa em um estado que não pode ser tornado sensível pelo uso de uma linguagem 'de olhos abertos', uma gramática pré-fabricada e um enredo linear" ${ }^{\prime \prime}$.

Não se deve esquecer que o narrador crê possuir também uma parte narrativa. Embora esta seja a que menos lhe agrada, sente a necessidade de aproximar-se sem preconceitos também da via Hire, de analisar seus representantes, especialmente os realistas, que, segundo ele, compreendem a maior parte dela. Entretanto, quando ele se dispõe a isso, termina por admitir sua falta de conhecimento preciso em relação aos realistas:

Conocerles mejor es casi urgente. Porque a fin de cuentas tengo amplias nociones sobre ellos, pero últimamente, cuanto más creo conocerles, más siento que me alejo de la comprensión de su mundo. ¿Quiénes son en realidad los realistas? ¿Por qué siempre di por supuesto que sabía cómo eran? ¿Es cierto que el realismo es la fidelidad a las cosas del mundo tal como son? ¿Niegan la intemperie? ¿Es tan confortable su casa como imagino y por eso les tengo manía? ${ }^{17}$

Diante disso, o procedimento do narrador pode ser alvo do mesmo tipo de crítica que, segundo Adorno, o ensaio comumente recebe: seu caráter pouco sistemático. Além de partir de um conhecimento imperfeito de seu objeto, onde um rígido conhecimento a respeito do realismo seria esperado, poderia ainda ser dito contra ele, por exemplo, que a escolha pelo Finnegans Wake e pela narrativa de Simenon é demasiadamente limitada. Porém, para Adorno, diferentemente do pensamento oficial e estabilizado da ciência da teoria organizadas, o ensaio não busca uma conceituação universal, ele se relaciona de maneira cautelosa com a teoria e com os conceitos, pois nele o pensamento age sobre os elementos de sua livre escolha. No ensaio a exposição é
17. VILA-MATAS. Chet Baker piensa en su arte: ficción crítica, p. 276.
EM TESE
BELO HORIZONTE
v. 20
N. 3
SET.-DEZ. 2014
SANTOS. Vila-Matas pensa em sua arte: Os (des)caminhos da ficção crítica $\quad$ P. 107-118 
18. ADORNO. O ensaio como forma, p. 28.

19. ADORNO. O ensaio como forma, p. 44. valorizada, o "como" da expressão, em detrimento da delimitação do objeto por conceitos decretados de maneira definitiva, ele "[...] incorpora o impulso antissistemático em seu próprio modo de proceder, introduzindo sem cerimônias e 'imediatamente' os conceitos, tal como eles se apresentam. Estes só se tornam mais precisos por meio das relações que engendram entre si"18. No caso em questão, isso quer dizer que pelo fato do narrador de Vila-Matas não possuir um conteúdo pronto que possa ser transmitido de forma indiferente à exposição, o que se deve considerar como prioridade na análise de seu texto é a manutenção da "tensão entre a exposição e o exposto" ${ }^{19}$, a coordenação dos elementos, o retorno sobre si mesmo, isto é, o campo de forças criado pela relação conflituosa e pela dinâmica de interação recíproca entre as vias Finnegans e Hire. Segundo Adorno:

O ensaio [...] não admite que seu âmbito de competência lhe seja prescrito. Em vez de alcançar algo cientificamente ou criar artisticamente alguma coisa, seus esforços ainda espelham a disponibilidade de quem, como uma criança, não tem vergonha de se entusiasmar com o que os outros já fizeram. O ensaio reflete o que é amado e odiado, em vez de conceber o espírito como uma criação a partir do nada, segundo o modelo de uma irrestrita moral do trabalho. Felicidade e jogo lhe são essenciais. Ele não começa com Adão e Eva, mas com aquilo sobre o que deseja falar; diz o que a respeito lhe ocorre e termina
BELO HORIZONTE
20

N. 3 onde sente ter chegado ao fim, não onde nada mais resta a dizer: ocupa, desse modo, um lugar entre os despropósitos. Seus conceitos não são construídos a partir de um princípio primeiro, nem convergem para um fim último. ${ }^{20}$

Assim, o ensaio põe em dúvida o direito incondicional do método, funciona como crítica epistemológica ao método mesquinho que pretende não deixar escapar nada. Na concepção de Adorno, "[...] a ordem dos conceitos, uma ordem sem lacunas, não equivale ao que existe [...]"21, por isso o ensaio não almeja uma construção fechada ${ }^{22}$, contrapondo-se sobretudo à tradição filosófica ocidental, arraigada desde Platão, que condena o mutável e o efêmero como indignos da filosofia. Ainda segundo Adorno, "o ensaio [...] não quer procurar o eterno no transitório, nem destilá-lo a partir deste, mas sim eternizar o transitório”23. É nesse sentido que no texto de Vila-Matas o pouco rigor na escolha dos elementos do texto e a maneira errante como o narrador vai expondo suas ideias ${ }^{24}$ permitem trazer à luz a experiência do pensar, o pensamento atrelado às suas circunstâncias.

Finalmente, definindo livremente o que, de maneira não menos livre, denominou literatura Hire, o narrador a associa ao convencional e à repetição, a uma escrita que não apresenta problemas para a maioria dos leitores, marcadamente conservadora, constituída por personagens previsíveis e por tramas tradicionais. Ela estaria, portanto, fechada no que se
20. ADORNO. O ensaio como forma, p. 16-17.

21. ADORNO. O ensaio como forma, p. 25.

22. Destaca-se aqui uma passagem que deixa clara a disposição do narrador nesse sentido: “[...] desde el primer momento he de cultivar el equívoco de modo que pueda tener y no tener razón a la vez, mezclar la profundidad y el humor, ser y no ser, etcétera y el humor, ser y no ser, etcete
$[$ [...]". In: VILA-MATAS. Chet Baker piensa en su arte: ficción crítica, p. 293.

23. ADORNO. O ensaio como forma, p. 27.

24. "[...] dejo ahora que las ideas se crucen por mi sandero errático [...]" In: VILA-MATAS. Chet Baker piensa en su arte: ficción crítica, p. 287. 
25. VILA-MATAS. Chet Baker piensa en su arte: ficción crítica, p. 342.

26. Tradução de Augusto de Campos. Cf. CAMPOS; CAMPOS. Panaroma do Finnegans Wake, 40-41.

27. “Com riverrun (riocorrente), em letra minúscula, irrompe o Finnegans Wake, no meio de uma do volume. Joyce imaginou para o seu livro uma estrutura ar o seu livro uma estrutura aberta: a derradeira palavra prossegue na primeira, num 'continuum' romance. [...] No $1^{\circ}$ parágrafo, o princípio masculino e feminino Adão e Eva (no lno e feminino, Adăo e Eva (no caso, tambem, a Igreja de 'Adăo e Eva' às margen tema do 'ricorso' eublin) e o tema do ricorso de Vico, em vicus of recircutation - vicus significendo 'rua', mas ao mesmo tempo evocando Gis ao mesmo Vico a Vico Road, de Dublin; commodius aludind commodicus aludindo ao imperador Commodus, da Roma decadente (dicu. lat., há muito tempo). Na referencia a Howth Castle (localidade de Dublin) and Environs, insinuam-se as iniciais HCE, prenunciadoras de Humphrey Chimpden Earwicker, que há de substituir Finnegan." do Finnegans Wake, p. 111. refere ao uso de novas fórmulas e acomodada quanto à ostentação de vínculo estável entre palavra e referente. Todas essas características aparecem no texto de maneira muito fragmentada, apenas em seu final o autor se detém em um comentário mais extenso para, a seu modo, defini-la:

La literatura Hire nace de no poder aguantar el desorden atolondrado de la vida. O lo que es lo mismo: si la gran mayoría de los humanos se sienten impulsados a abandonar parcialmente el área Finnegans, es porque intuyen que su locura podría ir progresando sin cesar. Entonces organizan todo esto, organizan un sentido, se acogen al sillón de orejeras Hire. La literatura de ese estilo, la literatura Hire, simula que cree en el sentido, y en los vientos atolondrados del desorden se dedica a construir pequeños teatros fijos, mínimos teatros estables, teatrillos de alma, sucesos narrables; construye estilos propios, estilos que son farsas armadas sobre la nada. Y todo para no desesperar para no caer en el sinsentido más absoluto. Ser Hire tiene sus compensaciones cuando, satisfechos de haber engañado a nuestra angustia, al calor de un hogar supuestamente estable, hacemos como si nada, como si el mundo amparara serenamente un orden, una lógica sucesión de hechos en un escenario totalmente razonable e fuera de toda sospecha. $Y$ es as como alcanzamos de vez en cuando, en ráfagas que no llegan ni a momentos, una fugaz felicidad casi tangible. ${ }^{25}$
Em sua investigação errante, o narrador também recorre diretamente ao Finnegans Wake, se dispondo a analisar seu primeiro parágrafo, o qual se destaca abaixo junto a uma proposta de tradução em português:

riverrun, past Eve and Adam's, from swerve of shore to bend of bay, brings us by a commodius vicus of recirculation back to Howth Castle and Environs.

riocorrente, depois de Eva e Adão, do desvio da praia à dobra da baía, devolve-nos por um commodius vicus de recirculação devolta a Howth Castle Ecercanias. ${ }^{26}$

Desse trecho, o narrador destaca as referências ao rio Liffey e a Gianbattista Vico e sua concepção circular da história, tal como Joyce concebeu o Finnegans Wake, fazendo com que o livro comece no meio de uma frase e termine no meio de outra que pode ser reportada à primeira, formando um conjunto circular ${ }^{27}$. Porém, seu interesse se detém principalmente à palavra riocorrente ${ }^{28}$, como se ela se assemelhasse a seu percurso na noite, seu "riverrun de insomnio" 29 , seu "riverrun personal"30, afinal, reconhece que o texto que vai desenvolvendo ao longo da madrugada é também um "riocorrente", um work in progress, que prossegue sem procedimento ou método, seguindo o puro capricho de suas escolhas e ideias, umas carregando as outras. É assim que, “[...] ensayando tramas, o tramando ensayos [...]"31, o narrador decide ler um trecho
28. “Riverrun. Cuando hablo a solas me gusta especialmente farfullar esa palabra [...] Riverrun me suena a retiro, a meditación, pero también a corso de las cosas, a río de la vida, a río que me está conectando con el universo entero [...]". In: VILA-MATAS Chet Baker piensa en su arte: ficción crítica, p. 301.

29. VILA-MATAS. Chet Baker piensa en su arte: ficción crítica, p. 268.

30. VILA-MATAS. Chet Baker piensa en su arte: ficción crítica, p. 273.

31. VILA-MATAS. Chet Baker piensa en su arte: ficción crítica, p. 285.

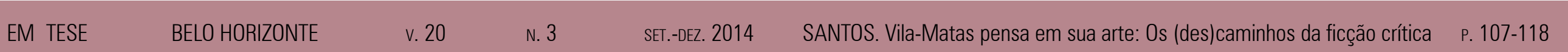


32. VILA-MATAS. Chet Baker piensa en su arte: ficción crítica, p. 284. de Les Fiançaille de Monsieur Hire. Ao fazê-lo, fica encantado com a prosa simples e sem rodeios de Simenon, percebe que também é maravilhoso ler relatos de traços tradicionais, pois, no fim das contas, "¿Qué haríamos sin historias?"32. Seu julgamento vacila e ele se surpreende consigo mesmo quando chega a pensar que, apesar das muitas diferenças, Finnegans e Hire talvez sejam modalidades diferentes de realismo. Para ele, o fato de, no fundo, serem apenas experiências da linguagem em diferentes níveis as aproxima.

Percebendo de modo mais intenso a duplicidade que possui em si, os pensamentos do narrador vão se desenvolvendo enquanto ele traz ao texto mais duas referências para compor sua análise: Viagem em volta do meu quarto, de Xavier de Maistre, e O Estranho caso do Dr. Jekyll e Mr. Hyde, de Robert Louis Stevenson. Quanto ao primeiro livro, não se deve perder de vista que o narrador está em um quarto na rua Pó, em Turim, local onde o livro foi escrito enquanto De Maistre cumpria prisão domiciliar, ou seja, um artifício extra de Vila-Matas para criar uma estrutura intertextual. Porém, o mais importante a destacar é o tema da identidade que ambos os livros trazem. Para o narrador de Viagem em volta do meu quarto, o homem é constituído por uma alma e por uma besta, os dois absolutamente distintos, "[...] mas tão encaixados um no outro, ou um sobre o outro, que é preciso que a alma tenha uma certa superioridade sobre besta para estar em situação de fazer a distinção" ${ }^{33}$. No caso do clássico romance de Stevenson, o Dr. Jekyll, após seus experimentos e infortúnios, afirma em sua confissão: “[...] o homem na verdade não é um, mas dois. [...] outros irão me ultrapassar nesse caminho; e eu arrisco a suposição de que o homem acabará sendo reconhecido como uma assembleia de inquilinos múltiplos, incongruentes e autônomos" ${ }^{34}$. É por meio do comentário desses dois textos que o narrador cria o contexto no qual vai pensar sua personalidade:

Últimamente, no hay día en que no recuerde que no acabo de tener nunca acceso a mi verdadero yo, quizá porque no lo modelé como una esencia estable, segura de sí misma, sino como una búsqueda conflictiva e inacabada de una verdad esquiva. Lo que, dicho sea de paso y teniendo en cuenta que estoy tratando de alojar con la máxima comodidad posible en mí mismo a dos arquetipos distintos de modos de enfocar la práctica literaria, puede a la larga resultar fértil. O no. ${ }^{35}$

A partir dessas características da personalidade do narrador podem ser vislumbrados outros traços essenciais do ensaio que o texto de Vila-Matas possui. No ensaio, muito mais que rigor classificatório, exige-se do ensaísta a espontaneidade imaginativa banida das práticas da ciência e dos discursos conceituais formalizados. Isso faz com que, desembaraçando-se da ideia tradicional de verdade, o narrador
33. MAISTRE. Viagem em volta do meu quarto, p. 31.

34. STEVENSON. O Estranho caso do Dr. Jekyll e Mr. Hyde, p. 86

35. VILA-MATAS. Chet Baker piensa en su arte: ficción crítica, p. 303. 
36. ADORNO. O ensaio como forma, p. 41.

37. VILA-MATAS. Chet Baker piensa en su arte: ficción crítica, p. 308.

38. “[...] ha ido comprendiendo que su intento de superar la Forma tan fosilizada del ensayo tradicional le ha conducido a un callejón oscuro [...] se ha alejado demasiado del texto radical momento imaginó que un momento imagino que escribiría y que no parece capaz de llevar a buen puero." In: VILA-MATAS. ficción crítica, p. 315 . esteja mais exposto à instabilidade. É diante desse contexto que Adorno afirma que "quando o espírito deseja mais do que a mera repetição e organização administrativas daquilo que já existe, ele acaba abrindo seu flanco; a verdade, fora desse jogo, seria apenas tautologia" ${ }^{36}$. De fato, partindo de hipóteses que vão multiplicando seus impasses, o narrador de Vila-Matas empreende uma busca incerta, mas essa busca tateante é justamente o preço a pagar por prescindir do método em nome da experiência mais aberta e da autonomia na exposição que o ensaio proporciona.

Com o passar da noite, o narrador vai perdendo o ânimo ante seu projeto. A duplicidade percebida por ele o faz afirmar: "[...] por paradójico que pueda ser, tantas dudas me dejan al final tan sólo frente a una certeza, frente a algo en verdad indudable: Finn y Hire se necesitan como la Bestia y el Alma" ${ }^{37}$. A parte final do texto vai ganhando contornos mais narrativos, aos poucos, a intenção do narrador de fazer um texto radical fica mais distante, vai convertendo-se em uma história tradicional. Ele admite que se encontra diante de um impasse, em um beco sem saída, percebe, enfim, que fracassou $^{38}$, tentou escrever ficção crítica, mas acabou contando uma história tradicional: a história de sua noite, com personagens, narrador e enredo. Todavia, os resultados parciais obtidos e o caráter de incompletude não são excluídos do âmbito do ensaio, porquanto

O ensaio [...] não deve, em seu modo de exposição, agir como se tivesse deduzido o objeto, não deixando nada para ser dito. É inerente à forma do ensaio sua própria relativização: ele precisa se estruturar como se pudesse, a qualquer momento, ser interrompido. O ensaio pensa em fragmentos, uma vez que a própria realidade é fragmentada; ele encontra sua unidade ao buscá-la através dessas fraturas, e não ao aplainar a realidade fraturada. A harmonia uníssona da ordem lógica dissimula a essência antagônica daquilo sobre o que se impõe. A descontinuidade é essencial ao ensaio; seu assunto é sempre um conflito em suspenso. ${ }^{39}$

Algo ainda deve ser dito a respeito da valorização da experiência intelectual pelo ensaio. Para Adorno, o ensaio é levado para além de si pelo desenvolvimento de seu pensamento, e não pela busca de seus fundamento ${ }^{40}$, nele o pensamento não avança em um único sentido e o pensador faz de si mesmo o palco da experiência intelectual, elegendo essa experiência como modelo. O narrador de Vila-Matas reconhece que não estava preparado para o ensaio radical que pretendia fazer, se sente abatido, porém, por meio de seu percurso noturno pôde reconhecer seus limites e está satisfeito pela tentativa de encontrar novas formas para tornar a literatura mais interessante ${ }^{41}$, afinal, segundo afirma:

Siempre he creído que no es conveniente detenerse en los logros y sí muy interesante escapar de ellos, buscar nuevos retos,
BELO HORIZONTE v. 20
N. 3
SET.-DEZ. 2014
SANTOS. Vila-Matas pensa em sua arte: Os (des)caminhos da ficção crítica $\quad$ P. 107-118
39. ADORNO. O ensaio como forma, p. 34-35.

40. Cf. ADORNO O ensaio como forma, p. 30 .

41. “[...] era una tarea apta para Finnegans con madera de titanes. sea, no era precisamente para el. Pero por lo menos lo ha intentado". In. VILA-MATAS. Chet Baker piensa en su arte: ficción
crítica, p. 315. 
42. VILA-MATAS. Chet Baker piensa en su arte: ficción crítica, p. 253. llevar con alegría la convicción de que, si bien nunca llegaremos a nada, merecen la pena los recodos de ese camino hacia la nada, porque en alguno de ellos habremos de cruzarnos con insensatas aventuras y tal vez también con formas nuevas inesperadas. ${ }^{42}$

A investigação do narrador noturno chegou ao fim, mas a narração de sua noite continua, ultrapassa a investigação inicial. O narrador passa a ler, contenta-se em ler, segundo ele, isto é o melhor que pode fazer no momento. O texto pretendido falhou, mas tudo que estava envolvido em sua elaboração está disponível ao leitor. A partir da narração, Vila-Matas integra de forma nítida o movimento e o contingente à investigação, volta-se ao individual, à experiência noturna do narrador, ao particular tantas vezes descartado em favor unicamente do conceito. É assim que o autor destaca a relação sinuosa do pensamento com o imediato, com seu entorno. $\mathrm{O}$ narrador pensa à medida que experimenta, tentando, por meio de sua escrita e de suas circunstâncias particulares, furtar-se como pode às mediações que tentam subordinar sua experiência.

"Chet Baker piensa en su arte" é um reflexo a mais de uma literatura que não deixa de se interrogar, de voltar o olhar para seus próprios procedimentos e de tentar avançar pela exploração de seus limites. Seu narrador não consegue concluir o ambicioso projeto de unir as tendências Finnegans e Hire, mas, fazendo os discursos crítico e narrativo se comunicarem, valoriza a liberdade de quem escreve e tenta renovar as formas de exposição do pensamento crítico ao não se resignar ao mero resultado da especulação e preferir apresentá-lo por meio da ficção em conjunto com a experiência que o torna possível: a experiência de um insone em um suposto quarto de Turim que se comunica com outra empreendida há mais de dois séculos por Xavier de Maistre, ambas movidas pela inquietude que sempre moverá a literatura em suas sucessivas rupturas.

Textos assim fazem a crítica ser ameaçada por seu próprio objeto. Narrando e ensaiando simultaneamente, o narrador afirma ter fracassado em sua tentativa de fazer um texto radical de ficção crítica tal como desejava, por outro lado, analisados de perto, do ponto de vista da investigação, os impasses e resultados aos quais chegou, bem como os elementos e artifícios por ele forjados para desenvolver sua análise sobre a linguagem literária, se diferenciam dos que apareceriam em uma investigação convencional menos por sua eficácia ou natureza que pelos meios da exposição que os trouxe à luz. Por tudo isso, esse caráter experimental se coloca como uma interessante oportunidade de comparar o alcance da associação entre crítica e ficção com os privilégios tradicionalmente atribuídos ao conjunto constituído por crítica e verdade.
EM TESE

BELO HORIZONTE

v. 20

N. 3

SET.-DEZ. 2014

SANTOS. Vila-Matas pensa em sua arte: Os (des)caminhos da ficção crítica P. 107-118 


\section{REFERÊNCIAS}

ADORNO, Theodor W. O ensaio como forma. In: Notas

de literatura I. Tradução de Jorge M. B. de Almeida. São Paulo: Duas Cidades; Ed. 34, 2003. p. 15-45.

BARTHES, Roland. Crítica e verdade. In: Crítica e verdade Tradução: Leyla Perrone-Moisés. São Paulo: Perspectiva, 2011. p. 185-231.

CAMPBELL, Joseph; ROBINSON, Henry Morton. Introdução a um assunto estranho. In: CAMPOS, Augusto de; CAMPOS, Haroldo de. Panaroma do Finnegans Wake. 4. ed. São Paulo: Perspectiva, 2001. p. 151-163.

CAMPOS, Augusto de; CAMPOS, Haroldo de. Panaroma do Finnegans Wake. 4. ed. São Paulo: Perspectiva, 2001.

CAMPOS, Augusto de. Outras palavras sobre Finnegans Wake. In: CAMPOS, Augusto de: CAMPOS, Haroldo de Panaroma do Finnegans Wake. 4. ed. São Paulo: Perspectiva, 2001. p. 195-198.

CAMPOS, Haroldo de. Panaroma em português. In: CAMPOS, Augusto de; CAMPOS, Haroldo de. Panaroma do Finnegans Wake. 4. ed. São Paulo: Perspectiva, 2001. p. 27-32.

MAISTRE, Xavier de. Viagem em volta do meu quarto. Tradução de Sandra M. Stroparo. São Paulo: Hedra, 2009.

PIGLIA, Ricardo. La lectura de la ficción. In Crítica y ficción. Buenos Aires: Planeta Argentina; Seix Barral, 2000. p. 9-19.
STEVENSON Robert Louis O Estranho caso do Dr. Jekyll e Mr. Hyde. Tradução de Braulio Tavares. São Paulo: Hedra, 2011.

VILA-MATAS, Enrique. Chet Baker piensa en su arte: ficcion crítica. In: Chet Baker piensa en su arte: relatos selectos. Buenos Aires: Debolsillo, 2012. p. 245-346. 